\title{
A Bicyclic Diterpenoid with a New 15,16-Dinorlabdane Carbon Skeleton from Leonurus japonicus and Its Coagulant Bioactivity
}

Fu Peng ${ }^{1,2}$, Liang Xiong ${ }^{1,3, *}$ and Xiao-Mei Zhao ${ }^{3}$

1 State Key Laboratory Breeding Base of Systematic Research, Development and Utilization of Chinese Medicine Resources, Sichuan Province and Ministry of Science and Technology, Chengdu 610075, China; E-Mail: fujing126@yeah.net

2 School of Life Sciences, Sichuan University, Chengdu 610064, China

3 Pharmacy College, Chengdu University of Traditional Chinese Medicine, Chengdu 610075, China; E-Mail: xiaomei08gz@163.com

* Author to whom correspondence should be addressed; E-Mail: xiling0505@126.com; Tel.: +86-28-6213-5056.

Received: 10 October 2013; in revised form: 29 October 2013 / Accepted: 5 November 2013 / Published: 11 November 2013

\begin{abstract}
A new 15,16-dinorlabdane diterpenoid $\mathbf{1}$ and a known labdane diterpenoid 2, together with three known ergosterols 3-5, were isolated from the EtOAc-soluble portion of the EtOH extract of Leonurus japonicus. Their structures were elucidated by physical and spectroscopic analysis. Compound $\mathbf{1}$ showed in vitro coagulant activity in the APTT, PT, TT, and FIB assays.
\end{abstract}

Keywords: Leonurus japonicus; dinorlabdane diterpenoid; coagulant activity

\section{Introduction}

Leonurus japonicus Houtt. (Lamiaceae) is an annual or biennial herbaceous plant widely distributed and cultivated in China. The dried herb is used in Traditional Chinese Medicine for the treatment of various diseases, especially menstrual disturbances, dysmenorrhea, and amenorrhea [1]. Our previous investigation on the plant resulted in the isolation of 19 secondary metabolites, including sesquiterpenoids, coumarins, lignans and phenylpropanoids [2,3]. In continuation of our research on bioactive natural products from L. japonicus, we have now carried out another study on the same 
EtOH extract. The present study has led to the isolation of diterpenoids and ergosterols, including a new norditerpenoid, (-)-3 $\alpha$-acetoxy-6 $\beta$-hydroxy-15,16-dinorlabd-8(9)-ene-13-yne-7-one (1), and four known compounds, leoheteronin F (2) [4], (22E,24R)-5 $\alpha, 8 \alpha$-epidioxyergosta-6,9(11),22-trien-3 $\beta$-ol (3) [5], (22E,24R)-5 $\alpha, 8 \alpha$-epidioxyergosta-6,22-dien-3 $\beta$-ol (4) [5], and (22E)-ergosta-6,9,22-triene-3 $\beta, 5 \alpha, 8 \alpha$ triol (5) [6] (Figure 1). Compound 1, an unusual bicyclic diterpenoid possessing a new 15,16-dinorlabd carbon skeleton, showed coagulant activity by shortening the activated partial thromboplastin time (APTT), prothrombin time (PT), and thrombin time (TT), and increasing the fibrinogen (FIB) levels. This paper reports the isolation, structure elucidation, and bioassays of these compounds.

Figure 1. Structures of compounds 1-5.

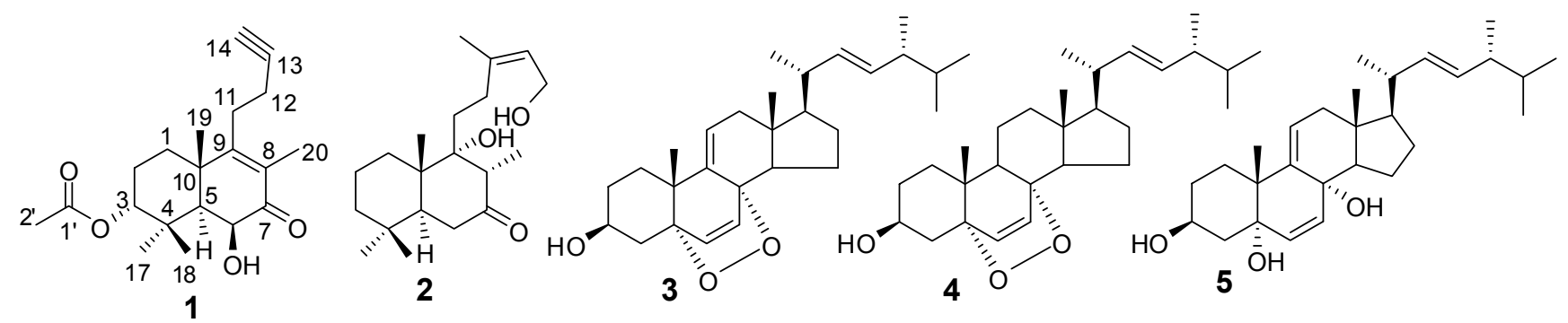

\section{Results and Discussion}

Compound 1 was obtained as a colorless oil, and its IR spectrum showed the presence of $\mathrm{OH}$ $\left(3,456 \mathrm{~cm}^{-1}\right)$, acetylenic bond (3,291 and 2,120 $\left.\mathrm{cm}^{-1}\right)$, carbonyl $\left(1,728\right.$ and 1,659 $\left.\mathrm{cm}^{-1}\right)$ and double bond $\left(1,607 \mathrm{~cm}^{-1}\right)$ groups. The molecular formula $\mathrm{C}_{20} \mathrm{H}_{28} \mathrm{O}_{4}$ of $\mathbf{1}$, with seven degrees of unsaturation, was indicated by the HRESIMS peak at $m / z 355.1883[\mathrm{M}+\mathrm{Na}]^{+}$(calcd. for $\mathrm{C}_{20} \mathrm{H}_{28} \mathrm{O}_{4} \mathrm{Na}, 355.1885$ ). The ${ }^{1} \mathrm{H}-\mathrm{NMR}$ spectrum of $\mathbf{1}$ displayed resonances attributable to five tertiary methyl groups $\left[\delta_{\mathrm{H}} 1.00\right.$ $\left(\mathrm{H}_{3}-17\right), 1.42\left(\mathrm{H}_{3}-18\right), 1.48\left(\mathrm{H}_{3}-19\right), 1.81\left(\mathrm{H}_{3}-20\right)$, and $\left.1.99\left(\mathrm{H}_{3}-2^{\prime}\right)\right]$, a monosubstituted acetylenic bond $\left[\delta_{\mathrm{H}} 2.47(\mathrm{t}, J=2.4 \mathrm{~Hz}, \mathrm{H}-14)\right]$, two oxymethines $\left[\delta_{\mathrm{H}} 4.60(\mathrm{t}, J=3.0 \mathrm{~Hz}, \mathrm{H}-3), 4.19\right.$ (dd, $J=4.2$, $3.0 \mathrm{~Hz}, \mathrm{H}-6)]$, an aliphatic methine $\left[\delta_{\mathrm{H}} 1.97(\mathrm{~d}, J=3.0 \mathrm{~Hz}, \mathrm{H}-5)\right]$, and four aliphatic methylenes between $\delta_{\mathrm{H}} 1.70$ and 2.60 (Table 1). It also displayed an exchangeable resonance assignable to a secondary hydroxy proton at $\delta_{\mathrm{H}} 4.53(\mathrm{~d}, J=4.2 \mathrm{~Hz}, \mathrm{OH}-6)$. The ${ }^{13} \mathrm{C}-\mathrm{NMR}$ and DEPT spectra of 1 showed a total of 20 carbon resonances corresponding to the above protonated units and six quaternary carbons, including a conjugated carbonyl $\left(\delta_{\mathrm{C}} 198.1\right)$ and a conjugated tetrasubstituted double bond $\left(\delta_{\mathrm{C}} 166.5\right.$ and 129.6) which implied an $\alpha, \beta$-unsaturated ketone system for compound 1 . The presence of an acetoxyl group in 1 was indicated by the signals of the ester carbonyl $\left(\delta_{\mathrm{C}} 170.4\right)$ in the ${ }^{13} \mathrm{C}-\mathrm{NMR}$ and the methyl $\left(\delta_{\mathrm{H}} 1.99\right)$ in the ${ }^{1} \mathrm{H}-\mathrm{NMR}$. In addition, the signals of the sp quaternary carbon $\left(\delta_{\mathrm{C}} 83.9\right)$ and sp methine $\left(\delta_{\mathrm{C}} 70.6, \delta_{\mathrm{H}} 2.47\right)$ were characteristic of a terminal alkynyl group. These spectroscopic data suggested that 1 was an unusual bicyclic dinorditerpenoid possessing an $\alpha, \beta$-unsaturated ketone system, a terminal alkynyl unit, and substitutions of a hydroxyl and an acetoxyl group.

The above conjecture was confirmed by $2 \mathrm{D}$ NMR data analysis. The proton and corresponding carbon resonances in the 2D NMR spectra of 1 were assigned by the gHSQC experiment. The $\mathrm{H}_{2}-1 / \mathrm{H}_{2}-2 / \mathrm{H}-3, \mathrm{H}-5 / \mathrm{H}-6$, and $\mathrm{H}_{2}-11 / \mathrm{H}_{2}-12$ coupling correlations in the gCOSY spectrum revealed three vicinal coupled systems (Figure 2). In the HMBC spectrum, two- and three-bond correlations of H-3/C-1, C-2, C-4, C-5, C-17, C-18, and C-1'; H-6/C-4, C-5, C-7, C-8, and C-10; OH-6/C-5 and C-6; 
$\mathrm{H}_{2}-11 / \mathrm{C}-8, \mathrm{C}-9$, C-10, C-12, and C-13; H-14/C-12; $\mathrm{H}_{3}-17$ and $\mathrm{H}_{3}-18 / \mathrm{C}-3$, C-4, and C-5; $\mathrm{H}_{3}-19 / \mathrm{C}-1$, C-5, C-9, and C-10; $\mathrm{H}_{3}-20 / \mathrm{C}-7, \mathrm{C}-8$, and C-9 (Figure 2), in combination with the vicinal coupled signals, indicated that the planar structure of 1 was 3-acetoxy-6-hydroxy-15,16-dinorlabd-8(9)-ene-13-yne-7-one.

Table 1. ${ }^{1} \mathrm{H}-(600 \mathrm{MHz})$ and ${ }^{13} \mathrm{C}-\mathrm{NMR}(150 \mathrm{MHz})$ data of $\mathbf{1}$ (in $\mathrm{Me}_{2} \mathrm{CO}-d_{6}, \delta$ in ppm, $J$ in $\mathrm{Hz}$ ).

\begin{tabular}{cccccc}
\hline No. & $\boldsymbol{\delta}_{\mathbf{H}}$ & $\boldsymbol{\delta}_{\mathbf{C}}$ & No. & $\boldsymbol{\delta}_{\mathbf{H}}$ & $\boldsymbol{\delta}_{\mathbf{C}}$ \\
\hline 1 & $1.73 \mathrm{~m}$ & 31.7 & 12 & $2.37 \mathrm{~m}$ & 18.5 \\
2 & $2.16 \mathrm{~m}, 1.72 \mathrm{~m}$ & 23.5 & 13 & - & 83.9 \\
3 & $4.60 \mathrm{t}(3.0)$ & 78.5 & 14 & $2.47 \mathrm{t}(2.4)$ & 70.6 \\
4 & - & 38.0 & 17 & $1.00 \mathrm{~s}$ & 27.5 \\
5 & $1.97 \mathrm{~d}(3.0)$ & 48.5 & 18 & $1.42 \mathrm{~s}$ & 24.4 \\
6 & $4.19 \mathrm{dd}(4.2,3.0)$ & 71.4 & 19 & $1.48 \mathrm{~s}$ & 22.1 \\
7 & - & 198.1 & 20 & $1.81 \mathrm{~s}$ & 11.9 \\
8 & - & 129.6 & $1^{\prime}$ & - & 170.4 \\
9 & - & 166.5 & $2^{\prime}$ & $1.99 \mathrm{~s}$ & 21.0 \\
10 & - & 41.5 & OH-6 & $4.53 \mathrm{~d}(4.2)$ & - \\
11 & $2.58 \mathrm{t}(7.8)$ & 29.5 & & & \\
\hline
\end{tabular}

The configuration of 1 was elucidated on the basis of the NOESY interactions and interproton coupling patterns [7-9]. A relatively small coupling constant of $\mathrm{H}-3(J=3.0 \mathrm{~Hz})$ and the distinct NOE between $\mathrm{H}-3$ and $\mathrm{H}_{3}-18$ (Figure 2) confirmed the assignment of $\mathrm{H}-3$ as $\beta$-equatorial orientation [8]. The H-5 and H-6 coupling constant $(J=3.0 \mathrm{~Hz})$ placed the two protons $c i$ s to each other in an $\alpha$-axial, $\alpha$-equatorial orientation, leaving the OH-6 as $\beta$-axial, which was confirmed by the NOE correlations of $\mathrm{H}_{3}-17$ with $\mathrm{H}-5$ and H-6. These data conclusively proved the new structure of 1 as (-)-3 $\alpha$-acetoxy-6 $\beta$ hydroxy-15,16-dinorlabd-8(9)-ene-13-yne-7-one.

Figure 2. (a) Key ${ }^{1} \mathrm{H},{ }^{1} \mathrm{H}-\mathrm{COSY}$ and HMBC correlations of 1; (b) Key NOESY correlations of $\mathbf{1 .}$

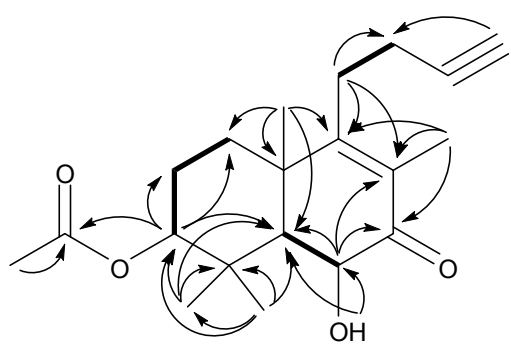

(a)

$$
\begin{aligned}
& { }^{1} \mathrm{H},{ }^{1} \mathrm{H}-\mathrm{COSY} \\
& \sim \operatorname{HMBC}(\mathrm{H} \rightarrow \mathrm{C})
\end{aligned}
$$

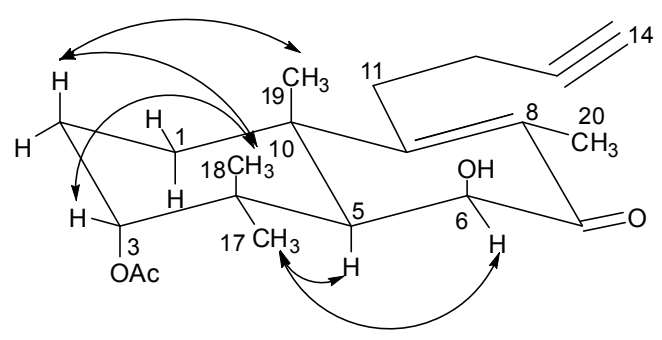

(b)

The coagulant activity of the compounds was examined by monitoring activated partial thromboplastin time (APTT), prothrombin time (PT), thrombin time (TT), and fibrinogen (FIB) levels. A summary of the results for compound $\mathbf{1}$ is shown in Table 2. At concentrations of $1 \mathrm{mg} / \mathrm{mL}$ and $0.1 \mathrm{mg} / \mathrm{mL}$, compound 1 shortened the APTT, PT, and TT and increased the content of FIB. Compared to the normal saline control group, they were statistically significant ( $p<0.05$ or $p<0.01$ ), except for the PT at $0.1 \mathrm{mg} / \mathrm{mL}$. Although there was no statistical difference in the APTT, PT, and TT between the group of $0.01 \mathrm{mg} / \mathrm{mL}$ and the normal saline group, treatment with compound $\mathbf{1}$ at this concentration resulted in obviously increased FIB $(p<0.05)$. The above results showed that compound 1 had coagulant 
activity via multiple pathways. Other isolated compounds were inactive in the blood coagulation assay at the concentrations of $1 \mathrm{mg} / \mathrm{mL}, 0.1 \mathrm{mg} / \mathrm{mL}$, and $0.01 \mathrm{mg} / \mathrm{mL}$.

Table 2. Coagulant activity of compound $\mathbf{1}^{\mathrm{a}}$.

\begin{tabular}{cccccc}
\hline Sample & Dose & APTT $(\mathbf{s})$ & PT $(\mathbf{s})$ & TT (s) & FIB (g/L) \\
\hline Control & Normal saline & $31.22 \pm 6.20$ & $9.98 \pm 0.54$ & $53.24 \pm 5.91$ & $1.59 \pm 0.08$ \\
Compound 1 & $1 \mathrm{mg} / \mathrm{mL}$ & $28.88 \pm 5.57 * *$ & $9.87 \pm 0.47 *$ & $49.94 \pm 3.46 *$ & $1.64 \pm 0.03 *$ \\
& $0.1 \mathrm{mg} / \mathrm{mL}$ & $29.66 \pm 4.90 *$ & $9.94 \pm 0.44$ & $50.77 \pm 4.43 *$ & $1.66 \pm 0.03 *$ \\
& $0.01 \mathrm{mg} / \mathrm{mL}$ & $31.38 \pm 4.87$ & $10.00 \pm 0.49$ & $53.28 \pm 3.98$ & $1.65 \pm 0.06 *$ \\
\hline
\end{tabular}

${ }^{\mathrm{a}}$ Each value represents the means $\pm \operatorname{SEM}(\mathrm{n}=10) ; * p<0.05$ as compared to control; ** $p<0.01$ as compared to control.

\section{Experimental}

\subsection{General}

NMR spectra were recorded on a INOVA-500 or Bruker-AVIIIHD-600 spectrometers. HRESIMS were measured with a Waters Synapt $\mathrm{G}_{2}$ HDMS. IR spectra were recorded on a Nicolet 5700 FT-IR microscope instrument (FT-IR microscope transmission). Optical rotations were measured with a PerkinElmer 341 plus. Column chromatography was performed with silica gel (200-300 mesh, Yantai Institute of Chemical Technology, Yantai, China), MCI gel CHP 20P (75-150 $\mu \mathrm{m}$, Mitsubishi Chemical, Co., Tokyo, Japan), and Sephadex LH-20 (Amersham Pharmacia Biotech AB, Uppsala, Sweden). HPLC separation was performed on an instrument consisting of a Cometro 6000LDS pump and a Cometro 6000PVW UV/VIS detector with an Ultimate $(250 \times 10 \mathrm{~mm})$ preparative column packed with $\mathrm{C}_{18}(5 \mu \mathrm{m})$. TLC was carried out with glass precoated silica gel $\mathrm{GF}_{254}$ plates (Qingdao Marine Chemical Inc., Qingdao, China).

\subsection{Plant Material}

The L. japonicus herb was collected in May of 2012 from a field in Wenjiang District, Chengdu City, Sichuan Province, China. Plant identity was verified by Prof. Min Li (Chengdu University of TCM, Sichuan, China). A voucher specimen (SYMC-0522) was deposited at the School of Pharmacy, Chengdu University of TCM, China.

\subsection{Extraction and Isolation}

The air-dried herb of L. japonicus $(20 \mathrm{~kg})$ was extracted with $95 \% \mathrm{EtOH}(3 \times 160 \mathrm{~L})$ at room temperature for $3 \times 72 \mathrm{~h}$. The ethanolic extract was evaporated under reduced pressure to yield a dark brown residue $(1.2 \mathrm{~kg})$. The residue was suspended in $\mathrm{H}_{2} \mathrm{O}$ and then successively partitioned into EtOAc (400 g) and n-BuOH (160 g) fractions. The EtOAc extract was subjected to silica gel CC using a gradient elution of petroleum ether-acetone (100:1-0:1) to afford nineteen fractions $\left(\mathrm{F}_{1}-\mathrm{F}_{19}\right)$ based on TLC analysis. $\mathrm{F}_{6}$ was further separated by $\mathrm{MCI}$ with a gradient of increasing $\mathrm{MeOH}(50 \%-100 \%)$ in water to yield six subfractions $F_{6-1}-F_{6-6}$. The successive separation of $F_{6-4}$ with Sephadex LH-20 (petroleum ether- $\mathrm{CHCl}_{3}-\mathrm{MeOH}, 5: 5: 1$ ) and with PTLC (petroleum ether-EtOAc 5:1) yielded 1 (6 mg) 
and 2 (18 mg). $\mathrm{F}_{6-6}$ was purified via silica gel $\mathrm{CC}$ over petroleum ether-EtOAc (40:1-5:1) to get $\mathrm{F}_{6-6-1^{-}}$ $\mathrm{F}_{6-6-4}$. Separation of $\mathrm{F}_{6-6-2}$ by repeated PTLC (petroleum ether-EtOAc 5:1) and reversed-phase semipreparative HPLC (80\% $\mathrm{MeCN}$ in $\left.\mathrm{H}_{2} \mathrm{O}\right)$ yielded $3(7 \mathrm{mg}), 4(21 \mathrm{mg})$, and 5 (26 mg).

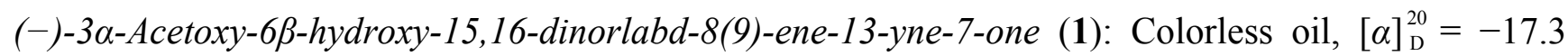
$(c=0.10, \mathrm{MeOH})$; IR vmax: 3456, 3291, 2941, 2874, 2120, 1728, 1659, 1607, 1461, 1375, 1248, 1128, 1047, $930 \mathrm{~cm}^{-1}$; ESI-MS m/z $355.2[\mathrm{M}+\mathrm{Na}]^{+}$; HRESI-MS: $\mathrm{m} / z 355.1883[\mathrm{M}+\mathrm{Na}]^{+}$(calcd. for $\left.\mathrm{C}_{20} \mathrm{H}_{28} \mathrm{O}_{4} \mathrm{Na}, 355.1885\right) ;{ }^{1} \mathrm{H}$ - and ${ }^{13} \mathrm{C}-\mathrm{NMR}$ data see Table 1.

\subsection{Blood Coagulation Assay [10]}

SD rats were lightly anesthetized with ether. Blood was immediately taken from the femoral artery and anticoagulated with $3.8 \%$ trisodium citrate $(9: 1, \mathrm{v} / \mathrm{v})$. Plasma was obtained by centrifugation of the whole blood at 3,500 $\mathrm{g}$ for $10 \mathrm{~min}$. Then, the plasma $(200 \mu \mathrm{L})$ was mixed with $20 \mu \mathrm{L}$ of tested compounds or normal saline and incubated for $5 \mathrm{~min}$ at $37{ }^{\circ} \mathrm{C}$. PT, APTT, TT, and FIB were determined by an automatic coagulation analyzer (Sysmex CA-500, Kobe, Japan) according to the manufacturer's instructions. Data were expressed as mean \pm SEM (standard error of the mean) of at least three independent experiments. Statistical significance between two groups was determined using the Student's $t$-test and a $p$-value of $<0.05$ was considered as significant.

\section{Conclusions}

Plants of the genus Leonurus are known to contain terpenoids, especially labdane diterpenoids. Previous phytochemical investigations on L. japonicus have led to the isolation of more than 35 labdane diterpenoids [4,9,11-17]. In the present study, two labdane diterpenoids 1-2 and three ergosterols 3-5 were obtained from the EtOAc soluble fraction of the EtOH extract of L. japonicus. It is worth mentioning that compound $\mathbf{1}$ is an unusual norditerpenoid with a new 15,16-dinorlabdane carbon skeleton. In addition, ergosterols were isolated from the genus Leonurus for the first time. In the in vitro assay, compound 1 showed an effect on blood coagulation. The APTT, PT, and TT were shortened and the FIB level was increased simultaneously by compound 1, which suggested the compound was a potential coagulant.

\section{Supplementary Materials}

Supplementary materials can be accessed at: http:/www.mdpi.com/1420-3049/18/11/13904/s1.

\section{Acknowledgments}

Financial support from the Natural Sciences Foundation of China (NSFC, Grant No. 81303209) and Sichuan Science and Technology Basic Research Program (Grant No. 2012JYZ005) is acknowledged.

\section{Conflicts of Interest}

The authors declare no conflict of interest. 


\section{References}

1. Commission of Chinese Pharmacopoeia. Pharmacopoeia of the People's Republic of China; Chemical Industry Press: Beijing, China, 2010; Volume 1, pp. 272-273.

2. Xiong, L.; Zhou, Q.M.; Peng, C.; Xie, X.F.; Guo, L.; Li, X.H.; Liu, J.; Liu, Z.H.; Dai, O. Sesquiterpenoids from the herb of Leonurus japonicus. Molecules 2013, 18, 5051-5058.

3. Zhou, Q.M.; Peng, C.; Li, X.H.; Xiong, L.; He, C.J.; Guo, L.; Cao, Z.X.; Liu, Z.H. Sesquiterpenoids from the herb of Leonurus japonicus. Biochem. Syst. Ecol. 2013, 51, 101-103.

4. Hung, T.M.; Luan, T.C.; Vinh, B.T.; Cuong, T.D.; Min, B.S. Labdane-type diterpenoids from Leonurus heterophyllus and their cholinesterase inhibitory activity. Phytother. Res. 2011, 25, 611-614.

5. Cateni, F.; Doljak, B.; Zacchigna, M.; Anderluh, M.; Piltaver, A.; Scialino, G.; Banfi, E. New biologically active epidioxysterols from Stereum hirsutum. Bioorg. Med. Chem. Lett. 2007, 17, 6330-6334.

6. Ponce, M.A.; Ramirez, J.A.; Galagovsky, L.R.; Gros, E.G.; Erra-Balsells, R. A new look into the reaction between ergosterol and singlet oxygen in vitro. Photochem. Photobiol. Sci. 2002, 1, 749-756.

7. Wu, H.; Fronczek, F.R.; Ferreira, D.; Burandt, C.L., Jr.; Zjawiony, J.K. Labdane diterpenoids from Leonurus sibiricus. J. Nat. Prod. 2011, 74, 831-836.

8. Moon, H.T.; Jin, Q.; Shin, J.E.; Choi, E.J.; Han, H.K.; Kim, Y.S.; Woo, E.R. Bis-spirolabdanetype diterpenoids from Leonurus sibiricus. J. Nat. Prod. 2010, 73, 123-126.

9. Seo, H.K.; Kim, J.S.; Kang, S.S. Labdane diterpenes and flavonoids from Leonurus japonicus. Helv. Chim. Acta 2010, 93, 2045-2051.

10. Zhou, J.J.; Xing, N.; Chen, J.; Shi, J.W.; Su, G.L. Effect of artificial colloids on blood coagulation during shock stage of severe burn injury. Chin. Med. J. 2013, 126, 3334-3339.

11. Hon, P.M.; Lee, C.M.; Shang, H.S.; Cui, Y.X.; Wong, H.N.C.; Chang, H.M. Prehispanolone, a labdane diterpene from Leonurus heterophyllus. Phytochemistry 1991, 30, 354-356.

12. Hon, P.M.; Wang, E.S.; Lam, S.K.M.; Choy, Y.M.; Lee, C.M.; Wong, H.N.C. Preleoheterin and leoheterin, two labdane diterpenes from Leonurus heterophyllus. Phytochemistry 1993, 33, 639-641.

13. Giang, P.M.; Son, P.T.; Matsunami, K.; Otsuka, H. New labdane-type diterpenoids from Leonurus heterophyllus SW. Chem. Pharm. Bull. 2005, 53, 938-941.

14. Giang, P.M.; Son, P.T.; Matsunami, K.; Otsuka, H. New bis-spirolabdane-type diterpenoids from Leonurus heterophyllus SW. Chem. Pharm. Bull. 2005, 53, 1475-1479.

15. Romero-González, R.R.; Ávila-Núñez, J.L.; Aubert, L.; Alonso-Amelot, M.E. Labdane diterpenes from Leonurus japonicus leaves. Phytochemistry 2006, 67, 965-970.

16. Moon, H.I. Three diterpenes from Leonurus japonicus Houtt protect primary cultured rat cortical cells from glutamate-induced toxicity. Phytother. Res. 2010, 24, 1256-1259.

17. Gong, H.Q.; Wang, R.; Shi, Y.P. New labdane-type diterpenoids from Leonurus heterophyllus. Helv. Chim. Acta 2012, 95, 618-625.

Sample Availability: Not available.

(C) 2013 by the authors; licensee MDPI, Basel, Switzerland. This article is an open access article distributed under the terms and conditions of the Creative Commons Attribution license (http://creativecommons.org/licenses/by/3.0/). 